\title{
Astronomical Constants and Universal Code in Holy Book
}

\author{
Mohammad Tayseer Al-Tamimi ${ }^{1}$ \\ ${ }^{1}$ The National Center for Publishing, Jordan \\ Correspondence: Mohammad Tayseer Al-Tamimi, The National Center for Publishing, Jordan. E-mail: \\ kingbanitamim@yahoo.com \\ Received: May 26, 2020 \\ Accepted: June 26, 2020 \\ Online Published: July 31, 2020 \\ doi:10.5539/apr.v12n4p85 \\ URL: http://dx.doi.org/10.5539/apr.v12n4p85
}

\begin{abstract}
At the beginning of 1995, I was looking to produce a new concept of the Astronomical Period (AP) which may be determined by the shortest period of Lunar years which this period includes leap years and common years, just to get a simple formula for calculating the average length of the lunar year where I finally deduced the first formula about this average by using the simple math (the four elementary arithmetic operations).

By this rule, I methodically educed what I essentially considered it as an acceptable consequence which, indeed, encouraged me to do more research about the best resources that required to deal with the concept of (AP) where I found something like the hidden signals in Islamic Holy Book (The Great Qur'an) which led me by the elicitation method to get the perfect astronomical constants besides of an evolving conclusion about what I considered it as a scientific guide to the universal code.

What the exiting in this research is: these (perfect astronomical constants) had successfully passed the test of three physical laws in motion which means that the hypothesis of this research (elicitation method) is not arbitrary, and the conclusions of this research had truly deduced by innovative scientific basis.
\end{abstract}

Keywords: Universe, Code, Elicitation, Qur'an, Astrophysics, Altamimi

\section{Introduction}

If you observed the motion of Moon regarding to Earth's motion around the Sun with respect to fixed star, you will find that we have a specific period that is formed by the shortest AP which equals 19 Lunar years. And then we know that this period has two types of years: Leap Lunar year equals 355 days, and the common Lunar year equals 354 days, and when I tried to find any resources that confirm this observation by anyway, I found the Great Qur'an (Note 1) had mentioned the word of (year) in specific arrangement; seven times as singular form (year) and twelve times as plural form (years). Then I tried to use these details to figure out the average length of the

Lunar year $\left(L_{y}\right)$ by this formula; $L_{y}=\frac{(\text { seven Leap years })+(\text { twelve common years })}{A P}$.

Then, by substitution, I got the first astronomical constant, as follows:

$$
L_{y}=\frac{(355 \times 7)+(354 \times 12)}{19}=354.36842105263156 \text { days }
$$

When I tried to compare this result with Synodical lunar year (which equals 29.530588 days (Note 2) $\times$ 12 months $=354.367056$ days) (Note 3), I found that the difference is less than two minutes; $354.368421-$ $354.367056=0.001365$ day $=1.9656$ miutes.

\section{Purpose of This Research}

In this research, I try to get the answers for these questions, scientifically:

a) Do we have an acceptable scientific resource, outside of the usual scientific resources, to get the scientific data or astronomical constants?

b) Can we use the elicitation method to get the perfect scientific data?

c) Can we refer to holy books to formulate physical equations? 


\section{Research Hypothesis}

I will depend on the elicitation method (Note 4) to reach out to the perfect astronomical constants from The Great Qur'an, and try to test these constants on the basic physical laws in motion.

\section{The Difficult Mission}

My mission in this research is: how can I find out the average length of the Solar year $\left(S_{y}\right)$ as I found out the $\left(L_{y}\right)$ before? Because this constant will become the best key to go further in the hypothesis of this research.

As I think, there are three valid options to find out this constant:

1) The same way of Eq $(1) ;(7 \times 366)+(12 \times 365) \div 19=365.368421$ days, which has a big difference with Sidereal Year $(S Y)$.

2) Using the Astrophysical constant which is not meeting the purpose of this research.

3) Referring to the Holy Book (The Great Qur'an) and try to find out if there is an accurate constant or not.

Indeed, when I referred to The Great Qur'an (Note 5), I found that the word of (year) or (years) had been mentioned in 16 different chapters (Soras) within 19 verses had been labeled by specific serial numbers that may be arranged in specific forms (Note 6) to keep something like a secret in its relationships together. See Table-1 where I tried to use these relations to get what I assumed as the difference by the minutes $\left(\Delta_{m}\right)$ between Lunar day and Solar day by using the following formula:

$$
\Delta_{m}=\frac{n-s}{f}=\frac{858-16}{19}=44.31578947368421 \text { miutes }
$$

Table 1. Leap \& common years as mentioned in Qur'an

\begin{tabular}{|c|c|c|}
\hline Types & Sora's No. & Verse's NO. \\
\hline Year & $2^{\text {nd }}$ (Al-Baqarah) & 96 \\
\hline Year & $5^{\text {th }}$ (Al-Ma'idah) & 26 \\
\hline Years & $7^{\text {th }} \quad$ (Al-'A'raf) & 130 \\
\hline Years & $10^{\text {th }}$ (Yunus) & 5 \\
\hline Years & $12^{\text {th }}$ (Yusuf) & 42 \\
\hline Years & $12^{\text {th }}$ (Yusuf) & 47 \\
\hline Years & $17^{\text {th }}($ Al-'Isra') & 12 \\
\hline Years & $18^{\text {th }}$ (Al-Kahf) & 11 \\
\hline Years & $18^{\text {th }}$ (Al-Kahf) & 25 \\
\hline Years & $20^{\text {th }}$ (Taha) & 40 \\
\hline Year & $22^{\text {nd }}(A 1-H a j)$ & 47 \\
\hline Years & $23^{\text {rd }}$ (Al-Mu'minun) & 112 \\
\hline Years & $26^{\text {th }}$ (Ash-Shu'ara') & 18 \\
\hline Years & $26^{\text {th }}$ (Ash-Shu'ara') & 205 \\
\hline Year & $29^{\text {th }}$ (Al-'Ankabut) & 14 \\
\hline Years & $30^{\text {th }}(\mathrm{Ar}-\mathrm{Rum})$ & 4 \\
\hline Year & $32^{\text {nd }}$ (As-Sajdah) & 5 \\
\hline Year & $46^{\text {th }}$ (Al-'Ahqaf) & 15 \\
\hline Year & $70^{\text {th }}$ (Al-Ma`arij) & 4 \\
\hline 19 times $(f)$ & 16 Soras $(s)$ & Subtotal $=858(n)$ \\
\hline
\end{tabular}

Now, if the result of Eq (2) means that we have a real difference between Lunar day and Solar day by minutes, then I can use this result to find out the difference by days $\left(\Delta_{d}\right)$ between Solar year and Lunar year depending on the same shortest $A P$ (19 years) of Lunar year which has: Total days $\left(T_{d}\right)=(7 \times 355)+(12 \times 354)=$ 6733 days) by using the following formula: $\left(\frac{\Delta_{m}}{\text { day }}\right) \times\left(\frac{T_{d}}{A P}\right)=\Delta_{d}$.

By substitution, $\left(\Delta_{d}\right)$ becomes available, as follows:

$$
\Delta_{d}=\left(\frac{44^{\prime} .31578947368421}{1440^{\prime}}\right) \times\left(\frac{6733}{19}\right)=10.90563634964604 \text { days }
$$


You note that I used the total minutes of one day $\left(1440^{\prime}\right)$ to convert those minutes to a day, and I used the total days (6733) of the shortest astronomical period $(A P)$ which equals 19 years, to find $\left(\Delta_{d}\right)$ as shown in $\mathrm{Eq}(3)$ which is more accurate than other predictions (Note 7).

Now, I can use this result to find out the average length of the solar year, as follows:

$$
L_{y}+\Delta_{d}=S_{y}=365.2740574022775 \text { days }
$$

Then, when you initially compare these results with astronomical constants, we find that; $L_{y}-L Y=$ 1.9656 minutes, $S_{y}-S Y=25.4736$ minutes, and you'll finally find that these data are examinable, as I will show you soon. But before that, let me refer you to Table-2 just to check how much the hypothesis of this research is running well or not, it is acceptable or not, or how much it is accurate or not?

Table 2. Astronomical constants \& research's constants

\begin{tabular}{cccc}
\hline Concept & Symbol & Constant & Type \\
\hline Julian Calendar (Note 8) & $S_{c}$ & Solar Calendar & Calendar \\
Hijri Calendar & $H_{c}$ & Lunar Calendar & Calendar \\
Length of Year & $S Y$ & 365.25636 days & Sidereal year (Note 9) \\
Length of Year & $L_{y}$ & 354.368421 days & Lunar year \\
Date of Al-Hijra & $d_{H}$ & $622.00 \mathrm{~J}$ & Event \\
Length of Year & $S_{y}$ & 365.274057402 & Solar Year \\
Length of Year & LY & 354.367056 & Synodical year (Note 10) \\
\hline
\end{tabular}

Hence, I think, it is the best way to check these results by referring to these laws; $b^{2}=a^{2}\left(1-e^{2}\right)$ (Note 11), Earth's orbit $=2 \pi a$, and the velocity law $\left(v=\frac{2 \pi a}{t}\right)$, where we find that the Earth's orbital speed by using (SY) is growing up to $(29.876819 \mathrm{~km} / \mathrm{s})$, but by using $\left(S_{y}\right)$ I find this speed becomes $(29.875327 \mathrm{~km} / \mathrm{s})$ more accurate and very close to the astronomical data $(29.8759 \mathrm{~km} / \mathrm{s})$ (Note 12$)$.

Now, if you want to transform the Julian (Solar) calendar $\left(J_{c}\right)$ to Hijri calendar $\left(H_{c}\right)$, or from $\left(H_{c}\right)$ to $\left(J_{c}\right)$, remember that the Hijri calendar is depending on Lunar year $\left(L_{y}\right)$ and the event of Al-Hijra $(H)$ had happened on Sep $20^{\text {th }}$ 622.A.C (Note 13) where I consider this event as a constant $(H=622)$ in the following transformations where the time interval of $\left(H_{c}\right)$ is dividing by the time interval of solar year with adding the constant $(H)$ if you want to convert $\left(H_{c}\right)$ to $\left(J_{c}\right)$, but if you want to convert $\left(J_{c}\right)$ to $\left(H_{c}\right)$ you have to deduct $(H)$ from the time interval of $\left(J_{c}\right)$ and then divide the result on the time interval of the Lunar year, as follows:

$$
\begin{gathered}
J_{c}=\left(\frac{H_{c} \times L_{y}}{S_{y}}\right)+H \\
H_{c}=\frac{\left(J_{c}-H\right)\left(S_{y}\right)}{L_{y}}
\end{gathered}
$$

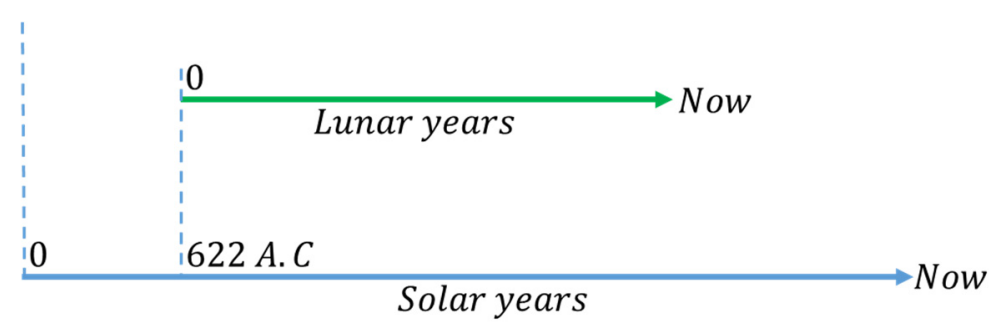

Figure 1. Confused image of calendars depending on time interval

It is easy now to use these transformations to check how much the elicitation method is scientifically strong and true, with respecting to the following facts:

a) Hijri calendar and Julian calendar have different starting (different origins). 
b) Lunar years are shorter than solar years (time interval of the Lunar year is shorter than the time interval of the Solar year). See Figure 1.

c) For perfect transformation, try to depend on the perfect results of Eqs (1-4) including all fractional numbers.

d) These transformations may explain the verse (25) in Surat Al-Kahf (18) which says: "and they remained in their cave for three hundred years and exceeded nine" where it is understood from this verse that: those persons had remained in their cave 300 solar years which equals 309 lunar years; $\left(300 \times S_{y}\right) \div\left(L_{y}\right)=309$. (Note 14)

Anyway, if you have any fractions in any result of these transformations, just pay attention to do the following:

a) If the fraction less than $50 \%$, just remove it from the result.

b) If the fraction more than $50 \%$, make it as $(+1)$ and add it to the result.

c) The accurate result depends on the full perfect results of Eqs (1-4).

\section{Mysterious Code}

Maybe these transformations seem as universal symphony, especially when we try to apply it for more than forty thousand years as shown in figure- 2 or Table-3 where we have some consequences worth to focus on it, like:

a) The solar calendar still bigger than the lunar calendar until a specific date (20800 A.C) which this date is the end of first Great Astronomical Period (GAP).

b) When the first $(G A P)$ is completed, the solar and the lunar calendars are shown as the same (become equaled).

c) After that date (20800 A.C), the lunar calendar is going to be bigger and bigger than the solar calendar.

d) The difference between the solar calendar and the lunar calendar seems as harmonious pulse as shown in column

(D) of Table 3.

e) The relationship between the solar and the lunar calendars still harmonious until 41000 A.C. Compare Figure 1 with Figure 2 where the present time is the best examine of these transformations; these two calendars have different starting, different time intervals, but they have the same shared point which is the present time (Now). Synchronization is an important scientific measurement in this case. See Figure 3.

f) The surprise appears suddenly as a missed period when these calendars cross the second great AP (41600 A.C).

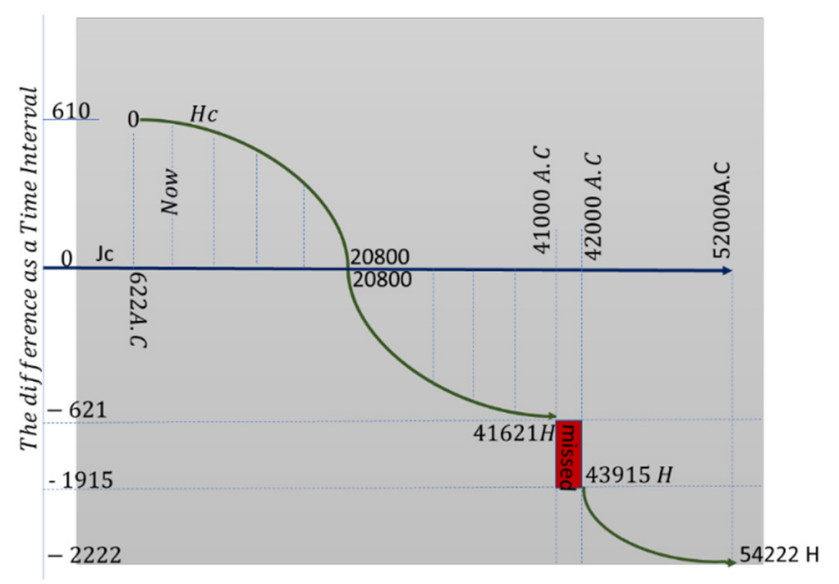

Figure 2. The curve of Hijri calendar \& Missed period

g) But, when I tried to apply these transformations for a long period of these calendars, I found some conclusions as shown in Table-3, where it led me to what I considered as a coding language or mysterious code. Note; by using transformation (6) I show you how solar calendar and Lunar calendar are going together $(A \equiv B)$ along the time where column $(C)$ shows you the differences between these calendars $(A-B=C ; 1000-390=610)$, but if we want to see the average of the changes on column (C) I deduct the initial $(C)$ from the updated $\left(C^{\prime}\right) ;(610-$ $580=031)$ to get some results, like: $(030,031, \ldots$ etc $)$ which seem along of column (D) as universal pulses where this way is applied in the last column $(E) ;\left(E=D-D^{\prime}\right)$ also, to discover what I considered as a mysterious code; $(000,000,000,000,001,001,000,000,001,001,000,000,001,001,000,000,000 \ldots . .$. etc $)$. 
Table 3. Symphony of the universe and the coding language

\begin{tabular}{|c|c|c|c|c|}
\hline $\mathrm{A}$ & B & $\mathrm{C}$ & $\mathrm{D}$ & $\mathrm{E}$ \\
\hline Julian calendar & Hijri calendar & Difference Of Jc \& Hc $(A-B)=\mathrm{C}$ & Average Of change & Mysterious Code \\
\hline 1000 & 390 & 610 & $\left(C-C^{\prime}\right)=D$ & \\
\hline 2000 & 1420 & 580 & 031 & $\left(D-D^{\prime}\right)=\mathrm{E}$ \\
\hline 3000 & 2451 & 549 & 031 & 000 \\
\hline 4000 & 3482 & 518 & 031 & 000 \\
\hline 5000 & 4513 & 487 & 031 & 000 \\
\hline 6000 & 5544 & 456 & 031 & 000 \\
\hline 7000 & 6574 & 426 & 030 & 001 \\
\hline 8000 & 7605 & 395 & 031 & 001 \\
\hline 9000 & 8636 & 364 & 031 & 000 \\
\hline 10000 & 9667 & 333 & 031 & 000 \\
\hline 11000 & 10697 & 303 & 030 & 001 \\
\hline 12000 & 11728 & 272 & 031 & 001 \\
\hline 13000 & 12759 & 241 & 031 & 000 \\
\hline 14000 & 13790 & 210 & 031 & 000 \\
\hline 15000 & 14820 & 180 & 030 & 001 \\
\hline 16000 & 15851 & 149 & 031 & 001 \\
\hline 17000 & 16882 & 118 & 031 & 000 \\
\hline 18000 & 17913 & 87 & 031 & 000 \\
\hline 19000 & 18944 & 56 & 031 & 000 \\
\hline 20000 & 19974 & 26 & 030 & 001 \\
\hline 21000 & 21005 & -5 & 031 & 001 \\
\hline 22000 & 22036 & -36 & 031 & 001 \\
\hline 23000 & 23067 & -67 & 031 & 000 \\
\hline 24000 & 24097 & -97 & 030 & 001 \\
\hline 25000 & 25128 & -128 & 031 & 001 \\
\hline 26000 & 26159 & -159 & 031 & 000 \\
\hline 27000 & 27190 & -190 & 031 & 000 \\
\hline 28000 & 28221 & -221 & 031 & 000 \\
\hline 29000 & 29251 & -251 & 030 & 001 \\
\hline 30000 & 30282 & -282 & 031 & 001 \\
\hline 31000 & 31313 & -313 & 031 & 000 \\
\hline 32000 & 32344 & -344 & 031 & 000 \\
\hline 33000 & 33375 & -375 & 031 & 000 \\
\hline 34000 & 34405 & -405 & 030 & 001 \\
\hline 35000 & 35436 & -436 & 031 & 001 \\
\hline 36000 & 36467 & -467 & 031 & 000 \\
\hline 37000 & 37498 & -498 & 031 & 000 \\
\hline 38000 & 38528 & -528 & 030 & 001 \\
\hline 39000 & 39559 & -559 & 031 & 001 \\
\hline 40000 & 40590 & -590 & 031 & 000 \\
\hline 41000 & 41621 & -621 & 031 & 000 \\
\hline 42000 & 43915 & -1915 & 2536 & 2505 \\
\hline 43000 & 44945 & -1945 & 0030 & -2506 \\
\hline 44000 & 45976 & -1976 & 0031 & 0001 \\
\hline 45000 & 47007 & -2007 & 0031 & 0000 \\
\hline 46000 & 48038 & -2038 & 0031 & 0000 \\
\hline 47000 & 49068 & -2068 & 0030 & 0001 \\
\hline 48000 & 50099 & -2099 & 0031 & 0001 \\
\hline 49000 & 51130 & -2130 & 0031 & 0000 \\
\hline 50000 & 52161 & -2161 & 0031 & 0000 \\
\hline 51000 & 53192 & -2192 & 0031 & 0000 \\
\hline 52000 & 54222 & -2222 & 0030 & 0001 \\
\hline
\end{tabular}


Eventually, if we can scientifically imagine this real and strong relationship between the Hijri calendar and the Lunar calendar along the Solar calendar, then we are strongly invited to study that curve of the Hijri calendar as a reflection of Lunar calendar along the Solar calendar, to get more knowledge about our universe. See Figure 3 where we have to remember that:

a) These three calendars had not started together, but they are together, crossing the present time (now), at the same time.

b) The missed period seems like a confusing era, when this era has (1000 Solar years $=2294$ Lunar years $)$ which is impossible, depending on the transformations of this research, because these transformations said that: (1000 Solar years $=1031$ or 1030 Lunar years) which means that these transformations had predicted that we have something unusual when the second (GAP) will be completed.

c) The difficult mission is made by concluding the synchronization of the three calendars, and foresight the outlook of our galaxy, at least.

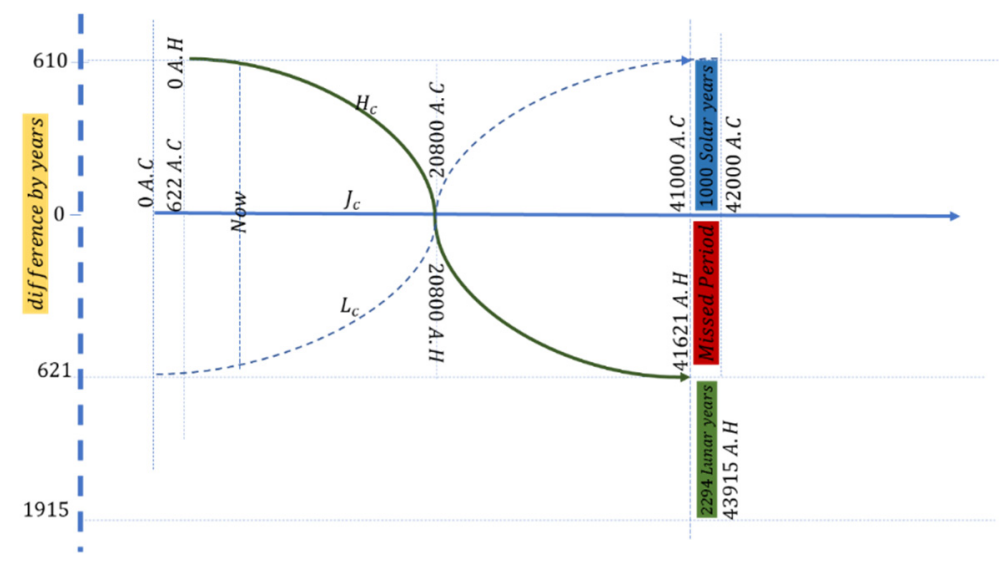

Figure 3. Synchronization of calendars \& Missed period

\section{Conclusion}

In this research the elicitation method had scientifically proved:

a) The accurate constants of the length of Lunar day, Lunar year, Solar day, Solar year and the difference between Solar and Lunar year as shown in Eqs (1-4).

b) Perfect astronomical transformations as shown in Eqs (5-6).

c) Other consequences as shown in Table 3 like; universal pulses (shown in column D) and mysterious code (shown in column E).

d) The missed period as shown in Figures 2, 3 and Table 3.

\section{Notes}

Note 1. The Holy Qur'an with English translation, Ahmadilyya Muslim Community, 2017.

Note 2. Synodical month (new moon to new moon) $=29.530588$ days. See; Allen's Astrophysical Quantities, Arthur N. Cox, fourth edition, springer, 2000, P. 308, chapter 12.7: Moon.

Note 3. See; Yury Grabovsky, Modern calendar and continued fractions, Department of Mathematics Temple University, 2000, p. 1.

Note 4. This is used for the first time, as I think, by a symbologist in Harvard University; Prof. Robert Langdon and cryptologist Sophie Neveu by following special symbols at many places in the world to prove a murder occurred in Louver Museum. See; Dan Brown, The Da Vinci code, Doubleday, USA, 2003.

Note 5. The Holy Qur'an, Arabic First Edition, Dar Annahda for Publication, Damascus, 1438 A.H.

Note 6. For example; by combining the numbers of these Verses, I found its subtotal equals $858(n=858)$. But the subtotal of the (year and Years) had been frequented nineteen times ( $\mathrm{f}=19)$ in sixteen Soras $(\mathrm{s}=16)$.

Note 7. See; Heiner Lichtenberg and Peter H. Richter, The Beauty of the Gregorian calendar, November 1998, p. 5.

Note 8. Note; Julian calendar is the same as the Solar calendar because all of them depend on the motion of our 
planet around the sun and itself, but the Lunar Calendar (Hijri calendar) is depending on the motion of Moon around the earth. See: Stephen P. Morse, The Julian Calendar and why we need to know about it, Association of Professional Genealogists Quarterly, March, 2014, pgs. 2-3. Also, see the introduction of; Thomas Djamaluddin, Calendar Conversion Program Used to Analyze Early History of Islam, Center for Application of Space Science National Institute of Aeronautics and Space (LAPAN) Bandung, Indonesia.

Note 9. Allen's Astrophysical Quantities, Arthur N. Cox, fourth edition, springer, 2000,p. 15.

Note 10. Allen's, p. 308, where you find synodic month equals 29.530588 days.

Note 11. See, Bradley W. Carroll \& Dale A. Ostlie; An Introduction to Modern Astrophysics, Weber State University, Addison-Wesley Publication Company, INC, NY, 2nd edition, 2006, p. 29.

Note 12. Depending on the distance between Sun and Earth on average is: $\left(a=15 \times 10^{7} \mathrm{~km}\right)$, see; Allen's Astrophysical Quantities, Arthur N. Cox, fourth edition, springer, 2000, p. 294, Table 12.1.

Note 13. See; Paul Lunde; The Beginning of Hijri Calendar, Saudi Aramco World Magazine, November/December, 2005. Other resources talked about a different date, like; Oct $5^{\text {th }} 621$ A.C. See Abstract of; Thomas Djamaluddin, Calendar Conversion Program Used to Analyze Early History of Islam, Center for Application of Space Science National Institute of Aeronautics and Space (LAPAN) Bandung, Indonesia. But the first date is more trust.

Note 14. Note: here I converted the time interval of 300 solar years to time interval of lunar years (it is different from the calendar's transformation).

\section{Conflict of interests}

The authors declare that there is no conflict of interests regarding the publication of this paper.

\section{References}

Ahmadilyya Muslim Community. (2017). The Holy Qur'an with English translation.

Bradley W. Carroll \& Dali A. Ostlie, (2007). An Introduction to Modern Astrophysics. San Francisco: Pearson Addison-Wesley.

Arthur N. Cox, (2000). Allen's; Astrophysical Quantities (4th ed.). Springer.

Dar Annahda for Publication, Damascus. (1438 A.H). The Holy Qur'an (Arabic 1st Ed.).

Djamaluddin, T. (n. d.). Calendar Conversion Program Used to Analyze Early History of Islam. Center for Application of Space Science National Institute of Aeronautics and Space (LAPAN) Bandung, Indonesia. Retrieved from https://dosya.diyanet.gov.tr/EAPDosya/EAPYayinDosya/M58.pdf

Grabovsky, Y. (2000). Modern calendar and continued fractions. Department of Mathematics, Temple University, USA. Retrieved from https://www.math.temple.edu/ yury/calendar/calendar.pdf

Langdon, R., \& Neveu, S. (2003). The Da Vinci Code. Doubleday, USA.

Lichtenberg, H., \& Richter, P. H. (November 1998). The Beauty of the Gregorian calendar.

Lunde, P. (November/December, 2005). The Beginning of Hijri Calendar. Saudi Aramco World Magazine.

Morse, S. P. (March, 2014). The Julian calendar and why we need to know about it. Association of Professional Genealogists Quarterly. Retrieved from https://stevemorse.org/juliancalendar/julian.htm

\section{Copyrights}

Copyright for this article is retained by the author(s), with first publication rights granted to the journal.

This is an open-access article distributed under the terms and conditions of the Creative Commons Attribution license (http://creativecommons.org/licenses/by/4.0/). 